\title{
Ultrafine particles in airways: a novel marker of COPD exacerbation risk and inflammatory status
}

This article was published in the following Dove Medical Press journal:

International Journal of COPD

\section{Einat Fireman Klein' \\ Yochai Adir' \\ Amir Krencel ${ }^{2}$ \\ Regina Peri \\ Bella Vasserman ${ }^{2}$ \\ Elizabeth Fireman ${ }^{3,4}$ \\ Aharon Kessel ${ }^{2}$ \\ 'Pulmonary Division, Carmel Medical Center, Rappaport Faculty of Medicine, Technion - Institute of Technology, Haifa, Israel; ${ }^{2}$ Division of Allergy and Clinical Immunology, Bnai Zion Medical Center, Rappaport Faculty of Medicine, Technion - Institute of Technology, Haifa, Israel; ${ }^{3}$ Institute of Pulmonary Diseases, National Laboratory Service for Interstitial Lung Diseases, Tel-Aviv Sourasky Medical Center, Tel Aviv, Israel; ${ }^{4}$ Department of Occupational and Environmental Medicine, Sackler School of Medicine, Tel Aviv University, Tel Aviv, Israel}

Correspondence: Einat Fireman Klein Pulmonary Division, Carmel Medical Center, Rappaport Faculty of Medicine, Technion - Institute of Technology, 7 Michal St, Haifa 34362 I2, Israel

Tel +97252426 690I

Email einatfire@gmail.com
Purpose: Ultrafine particles (UFP) are toxic due to their small size and penetration into deeper lung compartments. We aimed to evaluate the exhaled breath condensate (EBC)-UFP content as a reflection of inflammation and oxidative stress status in COPD patients and as an exacerbation risk marker.

Methods: EBC was collected by conventional methods. Particles were analyzed with NanoSight LM20. EBC carbonyl and 8-hydroxydeoxyguanosine (8-OHdG) levels were measured using ELISA kits. Study population (58 COPD patients and 40 healthy smoker and non-smoker controls) underwent spirometry, diffusion capacity, EBC testing, and blood sampling.

Results: Absolute eosinophil count, C-reactive protein (CRP), and lactate dehydrogenase in serum were elevated in the COPD group compared with the controls $(224 \mathrm{U} / \mathrm{L}, 5 \mathrm{mg} / \mathrm{L}$, and $391 \mathrm{U} / \mathrm{L}$ vs $154 \mathrm{U} / \mathrm{L}, 3 \mathrm{mg} / \mathrm{L}$, and $330 \mathrm{U} / \mathrm{L}, P=0.009, P=0.05$, and $P=0.004$, respectively). COPD patients had lower UFP concentrations in EBC compared with controls $(0.24 \mathrm{E} 8 / \mathrm{mL}$ vs $0.51 \mathrm{E} 8 / \mathrm{mL}, P \leq 0.001)$. A mirror image was detected in serum: COPD patients had higher UFP concentrations compared with controls $(9.8 \mathrm{E} 8 / \mathrm{mL}$ vs $6.7 \mathrm{E} 8 / \mathrm{mL}$, respectively, $P=0.03)$. EBC carbonyl and 8-OHdG levels were higher among COPD patients compared with controls (5.1 per $1 \mu \mathrm{g} / \mathrm{mL}$ protein and $0.036 \mathrm{ng} / \mathrm{mL}$ vs 0.41 per $1 \mu \mathrm{g} / \mathrm{mL}$ protein and $0.003 \mathrm{ng} / \mathrm{mL}$, $P=0.001$ and $P \leq 0.001$, respectively). EBC UFP concentrations were negatively correlated with pack years $(R=-0.44, P \leq 0.001)$ and positively correlated with $\mathrm{FEV}_{1}$ and diffusing lung capacity for carbon monoxide $(R=0.46,0.23, P \leq 0.001$ and $P=0.04$, respectively). Low EBC UFP concentrations $(\leq 0.18 \mathrm{E} 8 / \mathrm{mL})$ and CRP levels $\geq 5 \mathrm{mg} / \mathrm{L}$ were independent predictors of the frequent exacerbator phenotype (OR 3.6; 95\% CI: $1.06-7.97 ; P=0.04$ and OR 4.4; 95\% CI: $1.24-10.2 ; P=0.02$, respectively).

Conclusion: UFP content in EBC reflects the inflammatory state of airways. Low UFP concentrations in EBC and high in serum of COPD patients support our hypothesis that increased epithelial permeability could be the mechanism behind those findings.

Keywords: exhaled breath condensate, EBC, oxidative stress, COPD

\section{Introduction}

Ultrafine particles (UFP) have a critical role in inhaled particles' morbidity, mainly due to their extremely small size. The toxic effect of UFP is related to their large surface area, small size, and high penetration rate into deeper lung compartments, independently of their chemical properties. Oxidant injury of the airway epithelium plays a significant role in UFP-induced toxicity. ${ }^{1}$ Exposure of mice to inflammatory insults resulted in a unique UFP distribution pattern in bronchoalveolar lavage, with the UFP pattern returning to baseline after the inflammation was resolved. ${ }^{2}$ COPD is an inflammatory disease with a significant worldwide morbidity burden. ${ }^{3}$ Although smoking is still considered the primary risk factor for developing COPD, environmental 
exposure and various host factors, including genetics, airway hyper-responsiveness, and reduced baseline lung function in early adulthood, play an important role in disease severity and clinical course, ${ }^{4}$ as does air pollution. ${ }^{5}$

There is a growing interest in the exploration of new biomarkers for early detection, risk stratification, and phenotyping of COPD. Exhaled breath condensate (EBC) is a simple and noninvasive tool that involves the collection of exhaled air into a cooled tube. The fluid that is condensed from the exhaled breath contains substances from small- and medium-sized airways, which can be assessed for inflammatory and oxidative stress biomarkers. ${ }^{6}$

Biological monitoring was shown to be more informative than environmental monitoring in the surveillance and monitoring of occupationally exposed workers, ${ }^{7,8}$ yet most of our knowledge on particulate matter exposure and its effects on humans are based on environmental monitoring. It was recently showed that respiratory symptoms and airway inflammation are correlated with UFP content in the EBC of asthmatic children. ${ }^{9}$ Furthermore, exploring oxidative stress biomarkers in EBC supports the idea of personalized medicine as part of optimal surveillance and management of COPD patients. In this study, we aimed to evaluate UFP content and oxidative stress markers in EBC of COPD patients. Our innovative assumption is that the EBC content of UFP differs in inflamed lung tissue due to changes in airway permeability. If confirmed, this will establish EBC UFP content as a reflection of airway inflammatory status in COPD patients.

\section{Material and methods Study population}

The entire study population was recruited from Haifa district, a small district in the northern part of Israel. A total of 98 subjects were included, of whom 58 were COPD patients with different levels of disease severity and 40 were healthy smoker and non-smoker controls. The study subjects were patients who were attending an outpatient clinic, "The Center for Treatment of Lung Diseases" (Hagefen Clinic). Patients were clinically stable at the time of their visit to the clinic, and there had been no exacerbation of their COPD within the previous 4 weeks. The control group included smokers and non-smokers with no lung diseases consisting of hospitalized patients and the health care staff from Bnai Zion Medical Center. Those who had been hospitalized for any infectious or inflammatory conditions were excluded. All subjects underwent spirometry, diffusion capacity testing, EBC testing, and blood sampling. They all filled in a demographic and clinical questionnaire, and the patients took the COPD assessment test (CAT) as well. All subjects were asked to avoid smoking and any type of inhaled medication prior to EBC collection, as recommended by EBC guidelines. ${ }^{10}$

All subjects signed informed consent, and the study was approved by the Helsinki committees of the Bnai Zion and Carmel Medical Centers (Nos. 0051-14-BNZ and 0137-14$\mathrm{CMC}$, respectively).

\section{EBC samples' collection}

We used a portable condenser (TURBODECCS; ItalChill, Parma, Italy) specifically designed to collect EBC in clinical and workplace settings. The use of TURBO-DECCS (transportable unit for research on biomarkers obtained from disposable exhaled condensate collection systems) in this context has been validated. ${ }^{11}$ Briefly, subjects breathed into the collecting system for 5 minutes at normal tidal volume. Samples were stored at $-80^{\circ} \mathrm{C}$ until analysis. All EBC collections were performed in an environment with room temperature $\left(22^{\circ} \mathrm{C}-23^{\circ} \mathrm{C}\right)$ and humidity $(50 \%)$ controlled by a closed air-conditioning system.

\section{Pulmonary function tests (PFTs)}

PFTs were performed using a Masterlab spirometer (Masterlab E; Jaeger, Wurzburg, Germany). Measurements were carried out according to standard protocols of the American Thoracic Society guidelines. ${ }^{12}$

\section{Peripheral blood samples}

Blood samples were drawn by conventional methods. Samples were analyzed for complete blood count, C-reactive protein (CRP), bilirubin, and lactate dehydrogenase (LDH) in the hematology and chemistry labs of the Bnai Zion Medical Center.

\section{Questionnaire}

We used a demographic, occupational, and health data selfreported questionnaire. The questionnaire was validated by the Epidemiological and Preventive Medicine Department in the Tel Aviv University School of Public Health. The CAT score was used to assess disease-related symptoms. ${ }^{13}$ Exacerbation history of COPD patients during the past year was taken from medical records. Exacerbation was defined by the patient having been hospitalized due to COPD exacerbation/ pneumonia or treated as an outpatient with prednisone plus antibiotics due to worsening of respiratory symptoms.

\section{UFP measurement and analysis}

The size and concentration of the particles were assessed from the EBC samples with the NanoSight LM20 (NanoSight 
Ltd, Salisbury, UK). The particles contained in the samples were visualized by virtue of the light they scatter when illuminated by a laser light source. It is currently suitable for particles between 10 and $1,000 \mathrm{~nm}$. The camera captured video files of the particles moving under Brownian motion. The Nanoparticle Tracking Analysis (NTA software version 2.0) tracked many particles individually and using the Stokes-Einstein equation to calculate their hydrodynamic diameters. Approximately $0.3 \mathrm{~mL}$ of EBC was introduced into the viewing unit using a disposable syringe. Three videos of 60 seconds duration were recorded and analyzed for each sample. Total particle concentration, the percent of particles in the nano-size range, and the mean particle sizes were recorded. Particles between 100 and $500 \mathrm{~nm}$ were taken into consideration when calculating UFP concentrations, as particles $<0.5 \mu \mathrm{m}$ have a common deposition pattern. It is significant when evaluating inhaled particles' deposition pattern and subsequent dissemination in the respiratory tract and circulation. ${ }^{14}$ Moreover, transportation of particles $<0.5 \mu \mathrm{m}$ onto airspace surfaces is a consequence of collisions with gas molecules (Brownian diffusion), whereas larger particles are subject to gravitational and inertial forces..$^{15}$ All serum samples were diluted 1:10,000 by means of double-filtered distilled water, and $\leq 0.18 \mathrm{E} 8 / \mathrm{mL}$ was considered as a low EBC UFP concentration. "D90" represents the value of the particle diameter at $90 \%$ in the cumulative distribution, and the size in which $90 \%$ of the particles in the sample are smaller than it. Polystyrene nanometer beads 60, 100, 200, 400 , and $1,000 \mathrm{~nm}$ in size (Nanosphere ${ }^{\mathrm{TM}}$ Size Standards) were purchased from Thermo Fisher Scientific (Waltham, MA, USA).

\section{Oxidative stress markers}

Protein oxidation was determined in the EBC samples using the Protein Carbonyl ELISA kit (Cell Biolabs, Inc., San Diego, CA, USA) according to the manufacturer's instructions. Duplicates of the EBC samples were added to the 96-well protein-binding plate provided with the kit. A DNPH working solution was added to the samples and incubated with anti-dinitrophenyl antibody followed by HRP-conjugated secondary antibody. Absorbance at $450 \mathrm{~nm}$ was assayed using a VersaMax microplate reader. Protein carbonylation was calculated based on the bovine albumin standard provided with the kit. The total protein of samples was measured using the Bradford assay (Sigma-Aldrich, Rehovot, Israel). The procedure is based on the formation of a complex between the Bradford reagent and proteins in the EBC samples. A standard curve ranging from 1.2 to $2,500 \mu \mathrm{g} / \mathrm{mL}$ was used to identify low protein levels in the EBC. DNA oxidation was evaluated by measuring 8-hydroxydeoxyguanosine (8-OHdG), which is excreted during the repair of damaged DNA. EBC levels of 8-OHdG were determined using the sandwich ELISA, OxiSelect ${ }^{\mathrm{TM}}$ Oxidative DNA Damage ELISA kit (8-OHdG Quantitation), according to the manufacturer's instructions (Cell Biolabs, Inc.). Duplicates of the EBC samples were added on an 8-OHdG/BSA conjugate preabsorbed microplate. After a short incubation, an anti-8-OHdG monoclonal antibody was added, followed by an HRP-conjugated secondary antibody. 8-OHdG concentrations in the EBC samples were expressed as nanograms per milliliter according to a predetermined 8-OHdG standard curve.

\section{Statistical analyses}

Statistical analyses were performed using the SPSS software version 23.0 for Windows. Differences between particle characteristics and other parameters were compared by the $t$-test and the one-way ANOVA test and were considered significant at values below 0.05 . Spearman's coefficients were used to correlate the characteristics of the particles with oxidative stress markers and clinical parameters. The OR for frequent exacerbations was calculated using binary logistic regression.

\section{Results Subjects characteristics}

Demographic and clinical characteristics of COPD patients $(n=58)$ vs healthy controls $(n=40)$ are presented in Table 1 . PFTs and blood test results are shown in Table 2. The COPD patients had lower $\mathrm{FEV}_{1}$ and diffusing lung capacity for carbon monoxide (DLCO) values compared with healthy

Table I Demographic and clinical characteristics of the study population $(\mathrm{N}=98)$

\begin{tabular}{|l|l|l|l|}
\hline & $\begin{array}{l}\text { COPD } \\
\text { patients } \\
(\mathbf{n}=\mathbf{5 8})\end{array}$ & $\begin{array}{l}\text { Healthy } \\
\text { subjects } \\
(\mathbf{n}=\mathbf{4 0 )}\end{array}$ & P-value \\
\hline Age, years (mean \pm SD) & $68.3 \pm 8.6$ & $57.2 \pm 14.4$ & $0.00 \mathrm{I}$ \\
\hline Male, n (\%) & $46(79)$ & $21(52.5)$ & 0.05 \\
\hline Smoking, n (\%) & $10(17)$ & $13(32.5)$ & $<0.00 \mathrm{I}$ \\
Active & $46(79)$ & $10(25)$ & \\
Former $^{\mathrm{a}}$ & $2(3)$ & $17(42.5)$ & \\
\hline Never & $59.3 \pm 38.2$ & $13.6 \pm 20.5$ & $<0.00 \mathrm{I}$ \\
\hline Pack years, (mean \pm SD) & $3 \mathrm{I}(53)$ & $17(42.5)$ & 0.28 \\
\hline Occupational exposure, ${ }^{\mathrm{b}} \mathrm{n}(\%)$ & \\
\hline
\end{tabular}

Notes: ${ }^{2} \mathrm{~A}$ subject with a $\geq 20$ pack years history and self-reported as "former smoker". 'Occupational exposure to cleaning detergent, dye, asbestos, dust, fuel, sawdust, nitrogen acid, acetone, flour, sand, glue, smoke, heavy metals welding, plastic, and/or coal. Minimum of I year of exposure was taken as positive. 
Table 2 Pulmonary function and blood tests of the study population $(\mathrm{n}=98)$

\begin{tabular}{|c|c|c|c|}
\hline Mean \pm SD & $\begin{array}{l}\text { COPD } \\
\text { patients } \\
(n=58)\end{array}$ & $\begin{array}{l}\text { Healthy } \\
\text { subjects } \\
(n=40)\end{array}$ & $P$-value \\
\hline $\mathrm{FEV}, \%$ & $54 \pm 15.9$ & $93 \pm 17.5$ & $<0.001$ \\
\hline DLCO\% & $66.6 \pm 25.6$ & $78.5 \pm 12.4$ & 0.008 \\
\hline WBC $\left(\times 1,000 / \mathrm{mm}^{3}\right)$ & $8.3 \pm 1.7$ & $7.3 \pm 2.4$ & 0.02 \\
\hline EOS abs (cells $/ \mathrm{mm}^{3}$ ) & $224 \pm 163$ & $154 \pm 97$ & 0.009 \\
\hline CRP (mg/L) & $5 \pm 6.4$ & $3 \pm 3.1$ & 0.05 \\
\hline $\mathrm{LDH}(\mathrm{U} / \mathrm{L})$ & $391 \pm 93.1$ & $330 \pm 82.2$ & 0.004 \\
\hline
\end{tabular}

Abbreviations: CRP, C-reactive protein; DLCO, diffusing lung capacity for carbon monoxide; EOS abs, eosinophil absolute count; LDH, lactate dehydrogenase; WBC, white blood cells.

subjects ( $P \leq 0.001$ and $P=0.008$, respectively). The systemic inflammatory markers were significantly elevated in the COPD group. In this context, the patients had elevated peripheral eosinophil counts, $C R P$, and $\mathrm{LDH}$ values in serum compared with the controls $(P=0.009, P=0.04$, and $P=0.004$, respectively).

\section{UFP analysis in EBC and serum}

The mean size of the particles was $249 \pm 71 \mathrm{~nm}$ for the EBC samples and $227 \pm 36 \mathrm{~nm}$ for the serum samples of the study group, and their D90 was $398 \mathrm{~nm}$ for the EBC samples and $345 \mathrm{~nm}$ for the serum samples. The UFP values were analyzed in EBC and serum samples as shown in Figure 1. The UFP concentrations in EBC of COPD patients were significantly lower than that of the controls $(0.24 \mathrm{E} 8 / \mathrm{mL}$ vs $0.51 \mathrm{E} 8 / \mathrm{mL}$, respectively, $P \leq 0.001)$. A mirror picture was found in serum samples, a higher UFP concentrations were found in the COPD patients' serum samples compared with those of the controls $(9.8 \mathrm{E} 8 / \mathrm{mL}$ vs $6.7 \mathrm{E} 8 / \mathrm{mL}$, respectively, $P=0.03)$. These results were adjusted to gender and age.

A

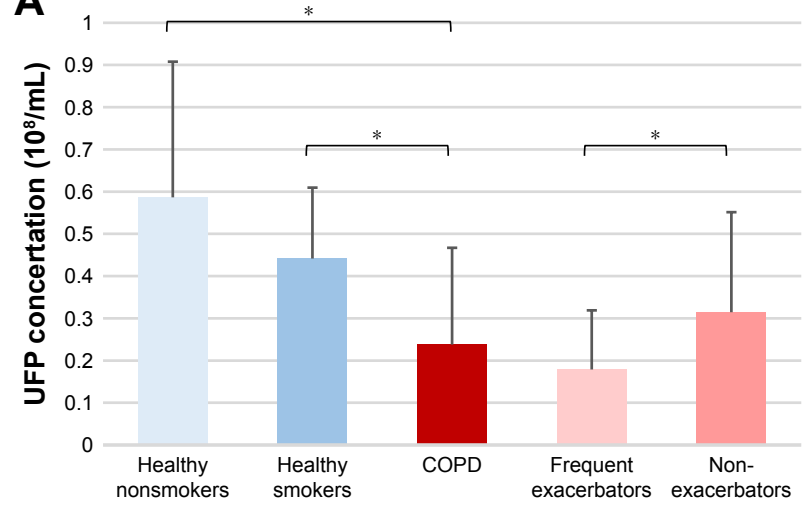

When subsequently the study population was divided according to smoking status it was revealed that the nonsmoker controls $(n=17)$ had the highest EBC UFP concentrations and the lowest serum UFP concentrations compared with the rest of the study population $(\mathrm{n}=81)(0.59 \mathrm{E} 8 / \mathrm{mL}$ and $5.6 \mathrm{E} 8 / \mathrm{mL}$ vs $0.3 \mathrm{E} 8 / \mathrm{mL}$ and $9.2 \mathrm{E} 8 / \mathrm{mL}, P \leq 0.001$ and $P=0.01$, respectively). As COPD patients had differences in terms of exacerbation rate, we analyzed the of UFP content according to this parameter. In fact, frequent exacerbators $(\geq 2 / 1$ with hospitalization per year) had lower UFP concentrations compared with the non-exacerbator patients (0.18 E8/mL, $\mathrm{n}=21$, vs $0.31 \mathrm{E} 8 / \mathrm{mL}, \mathrm{n}=19$, respectively, $P=0.03)$. We then analyzed several independent predictors for frequent exacerbations (Figure 2). Binary logistic regression revealed that low EBC UFP concentrations $(\leq 0.18$ $\mathrm{E} 8 / \mathrm{mL}$ ) and CRP levels $\geq 5 \mathrm{mg} / \mathrm{L}$ were independent predictors of the frequent exacerbator phenotype (OR, 3.6; 95\% CI: $1.06-7.97 ; P=0.04$ and OR, 4.4; $95 \%$ CI: $1.24-10.2$; $P=0.02$, respectively).

\section{Oxidative stress markers in EBC}

In further analysis, we focused our attention on oxidative stress parameters. We measured carbonyl and 8-OHdG levels in EBC as oxidative stress products of proteins and DNA, respectively, difference in those oxidative stress markers between study groups is presented in Figure 3. COPD patients $(n=38)$ had higher carbonyl levels in EBC compared with controls $(\mathrm{n}=29)(5.1$ per $1 \mu \mathrm{g} / \mathrm{mL}$ protein vs 0.41 per $1 \mu \mathrm{g} / \mathrm{mL}$ protein, $P \leq 0.001)$. The 8 -OHdG level in EBC was also elevated in COPD patients $(\mathrm{n}=40)$ compared with controls $(\mathrm{n}=26)(0.036 \mathrm{ng} / \mathrm{mL}$ vs $0.003 \mathrm{ng} / \mathrm{mL}, P=0.001)$. Subgrouping of the study population according to smoking status revealed no significant differences in the EBC carbonyl and 8-OHdG levels.

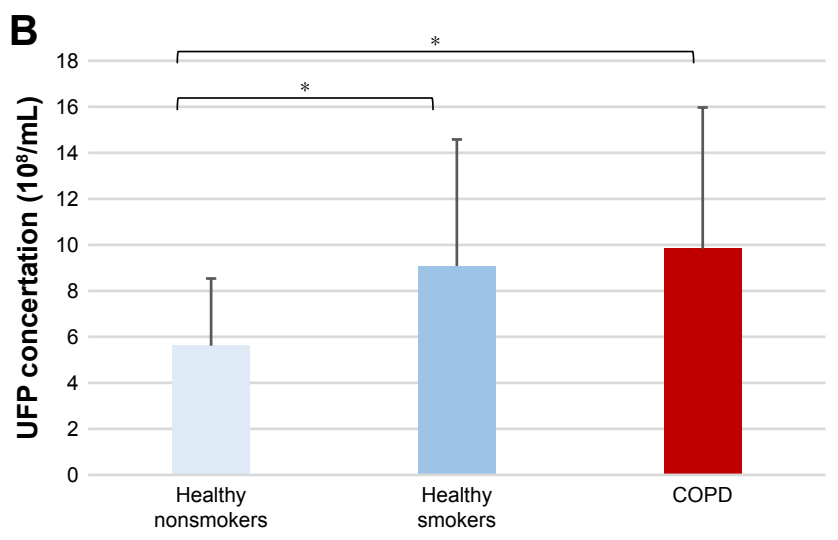

Figure I UFP concentration in exhaled breath condensate (A) and serum (B) of COPD patients and healthy controls. Notes: $* P \leq 0.05$. The differences between the COPD patients and the healthy controls were gender- and age-adjusted. Abbreviation: UFP, ultrafine particles. 


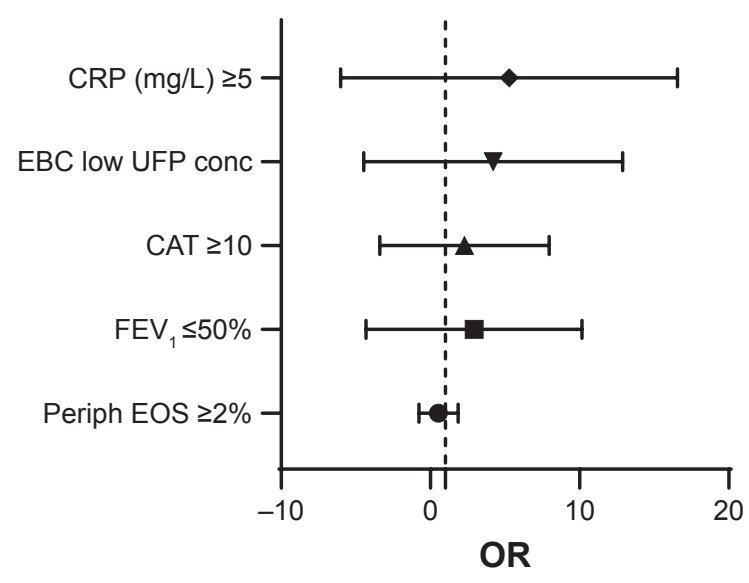

Figure 2 Frequent exacerbator phenotype risk ( $\geq 2 /$ I with hospitalization per year). Abbreviations: CAT, COPD assessment test; CRP, C-reactive protein; EBC, breath condensate; Periph EOS, peripheral eosinophils.

\section{UFP EBC content in correlation with oxidative stress and clinical parameters}

We also correlated UFP concentration samples and oxidative stress levels in EBC with selected clinical parameters (Table 3). There was a strong negative correlation between particle concentrations and pack years $(P \leq 0.001)$. FEV and DLCO levels correlated positively with UFP concentrations ( $P \leq 0.001$ and $P=0.04$, respectively). UFP concentrations correlated negatively with the systemic inflammation markers peripheral eosinophil count, $\mathrm{CRP}$, and LDH in serum ( $P=0.015, P=0.03$, and $P=0.02$, respectively). Finally, the carbonyl levels in EBC also correlated negatively with UFP concentrations $(P=0.05)$.

\section{Discussion}

The findings of the current study demonstrated a decreased UFP concentration in the EBC samples of COPD patients compared with healthy controls. These findings are the first step in the establishment of the EBC UFP content as an airway inflammation marker. The advantage of such a biomarker is that it reflects the local inflammation state of the lung with little or no influence of systemic inflammatory conditions. To the best of our knowledge, this is the first study to evaluate UFP content in EBC of COPD patients.

Our study population consisted of COPD patients and healthy controls - smokers and non-smokers. Systemic inflammation markers were elevated in the COPD group compared with the healthy subjects. These findings are compatible with the reports of other investigators who demonstrated local and systemic inflammation in healthy smokers compared with non-smokers, and which was further amplified in patients with chronic obstructive airways. ${ }^{16-18}$
We hypothesized that the UFP content in airways may be correlated with this inflammatory state. To verify this contention, we further analyzed their content in $\mathrm{EBC}$ and serum samples and found a lower UFP concentrations in the EBC of COPD patients compared with healthy subjects, with a mirror image in the serum samples; COPD patients had a higher UFP concentrations compared with the healthy subjects. Subgrouping the study population revealed that healthy non-smokers had the highest UFP concentrations in their EBC and the lowest serum UFP concentrations compared with the rest of the study population. These findings support our assumption that a healthy intact epithelial barrier should reduce translocation of particles while an increased epithelial permeability in inflamed airways will allow more UFP to penetrate and translocate into the circulation. A chronic inflammatory state involves changes in epithelial permeability. Both animal and human studies have shown elevated epithelial permeability in chronic smokers compared with nonsmokers. ${ }^{19}$ The observation that changes in respiratory epithelial permeability alter airways' UFP content had been demonstrated in a mice model in which the induction of lung inflammation resulted in a major shift of the UFP pattern towards larger particles, which can be explained by translocation of the smaller particles into the circulation. ${ }^{2}$ Moreover, these processes are not unique to the lung but can apply to important microcirculatory events that occur during an inflammatory process, including changes in vascular permeability, leukocyte recruitment and accumulation, and inflammatory mediator release. ${ }^{20}$ Consistent with those results, other in vitro studies showed that a decrease in the tight junctional resistance of mouse alveolar epithelial cell monolayers caused a drastic increase in translocation of engineered nanoparticles across the epithelial barrier. ${ }^{21}$ Many studies, both in human and animal models, have shown that inhaled nanoparticles can rapidly translocate into the circulation and accumulate in extrapulmonary organs. ${ }^{22-25}$

We further demonstrated a difference in UFP patterns in COPD patients with high exacerbation rate. Frequent exacerbators ( $\geq 2 / 1$ with hospitalization per year) had lower UFP concentrations in their EBC and higher CRP levels in serum compared with the nonexacerbator COPD patients. Moreover, low EBC UFP concentrations $(\leq 0.18 \mathrm{E} 8 / \mathrm{mL})$ and CRP levels $\geq 5 \mathrm{mg} / \mathrm{L}$ were found to be independent predictors of the frequent exacerbator phenotype. It has been reported that CRP levels in stable COPD patients are correlated with disease severity ${ }^{26,27}$ and increased risk for exacerbations, ${ }^{28}$ but there are no data regarding a possible cutoff for EBC UFP concentrations that can be related to disease activity. 
A

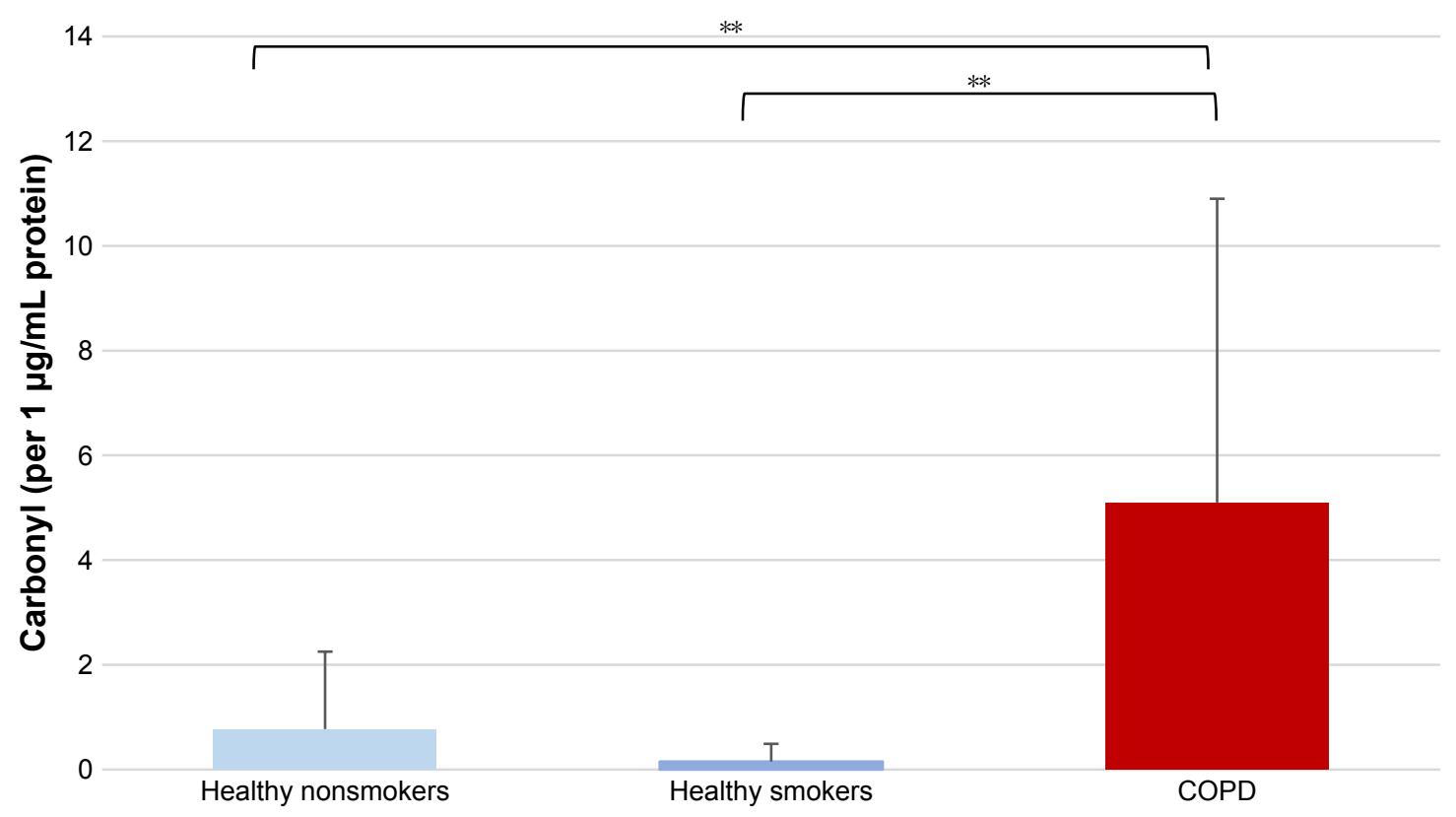

B

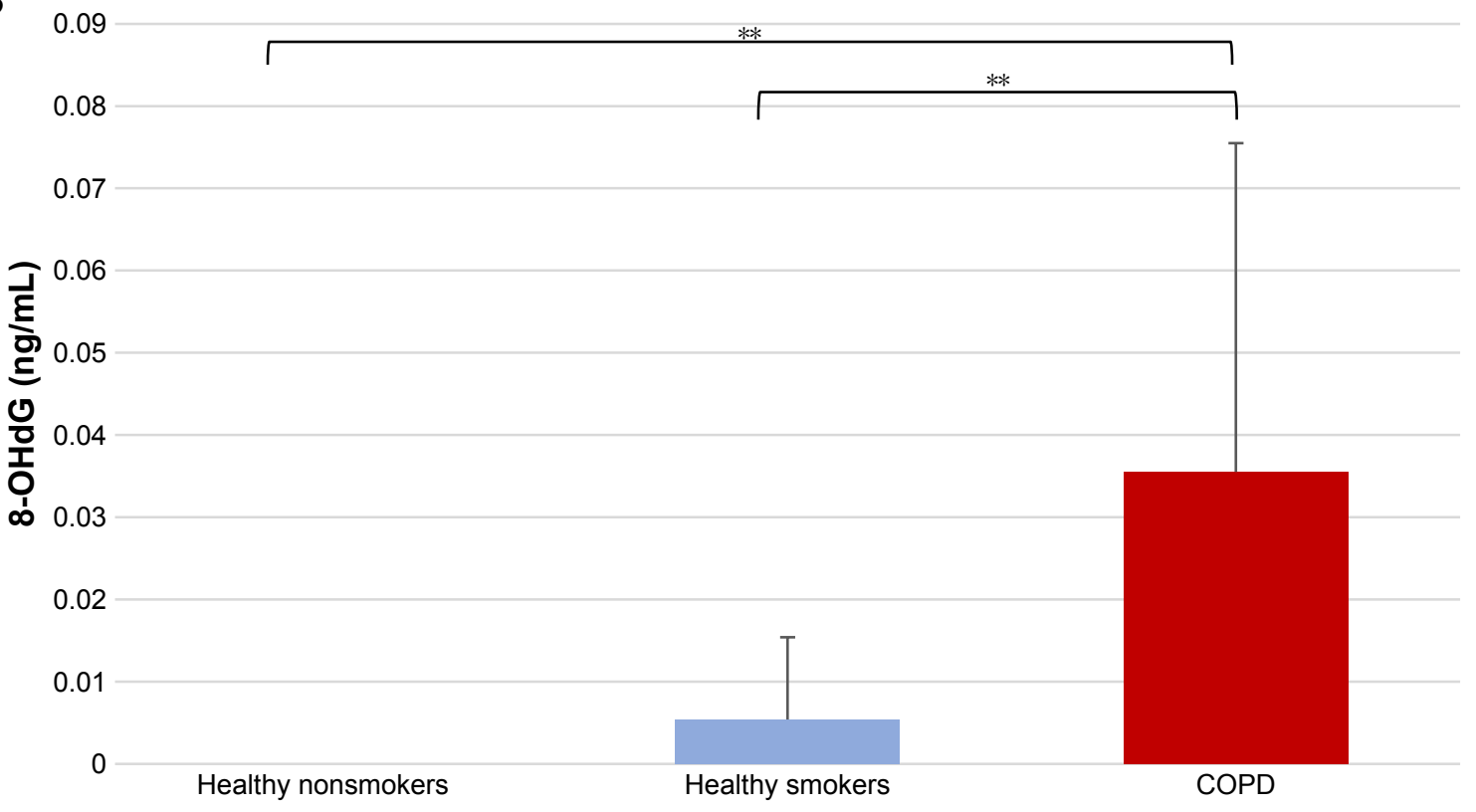

Figure 3 Carbonyl (A) and 8-OHdG (B) levels in exhaled breath condensate of the COPD patients and the healthy controls. Note: $* * P \leq 0.01$.

Thus, we present here for the first time a value of $0.18 \mathrm{E} 8 / \mathrm{mL}$ as a cutoff that can serve as such a predictor. These findings can predict that a patient with an EBC of UFP $\leq 0.18 \mathrm{E} 8 / \mathrm{mL}$ is more likely to belong to the frequent exacerbators group.
This also supports our hypothesis that lower UFP levels could be a reflection of airway inflammation and disease severity in COPD. Other human studies that exposed both healthy subjects and COPD patients to inhaled nanoparticles showed

Table 3 Clinical parameters, inflammation and oxidative stress markers in correlation with UFP concentrations in EBC

\begin{tabular}{|l|l|l|l|l|l|l|l|l|}
\hline & Pack years & FEV $\%$ & DLCO\% & Eos abs & CRP (mg/L) & LDH (U/L) & Carbonyl & 8-OHdG \\
\hline UFP in EBC $\left(10^{8} / \mathrm{mL}\right)$ & $R=-0.44^{* * *}$ & $R=0.46^{* * *}$ & $R=0.23^{*}$ & $R=-0.25^{*}$ & $R=-0.22^{*}$ & $R=-0.27^{*}$ & $R=-0.25^{*}$ & $R=-0.1$ \\
\hline
\end{tabular}

Note: $* * * P<0.001, * P \leq 0.05$.

Abbreviations: 8-OHdG, 8-hydroxydeoxyguanosine; CRP, C-reactive protein; DLCO, diffusing lung capacity for carbon monoxide; EBC, exhaled breath condensate; Eos abs, eosinophil absolute count; LDH, lactate dehydrogenase; UFP, ultrafine particle. 
that the deposition of particles increases with the severity of the disease. ${ }^{29}$

In this study, we estimated the internal personal-level burden of UFP by means of biological monitoring. There is a lack of biologically relevant personal exposure metrics for exposure to environmental-related particulate matter. Most urban environmental monitoring stations have too few sites, and they can hardly be considered representative of actual public exposure. Moreover, most of those stations are not capable of measuring UFP levels. Biological monitoring, in contrast, includes the most health-relevant assessments of human exposure to environmental pollutants and is a direct measurement of a given substance and its metabolites. It takes into consideration the accumulation of fine and UFP in airways. In addition, a recent study showed that biological monitoring of UFP concentrations in induced sputum correlated with clinical parameters and enabled mapping of wider areas compared with environmental monitoring. ${ }^{30}$ Our findings of low UFP concentrations in EBC of COPD patients together with the suggested mechanism may explain why COPD patients are apparently more vulnerable to ambient air pollution than the healthy population. ${ }^{31,32}$

Oxidative stress plays a central role in amplifying lung inflammation and subsequent exacerbation in COPD. To the best of our knowledge, this is the first study testing carbonyl and 8-OHdG levels in EBC of COPD patients. Carbonyl and 8-OHdG levels in EBC were higher among COPD patients compared with healthy subjects. Similarly, carbonyl level in BAL of cystic fibrosis patients was high compared with healthy subjects and correlated with neutrophilic inflammation level. ${ }^{33}$ Moreover, multiple studies have shown that $\mathrm{H}_{2} \mathrm{O}_{2}$ and lipid oxidation products are elevated in EBC of COPD patients and part of those biomarkers are correlated with disease severity. ${ }^{34}$

Regarding clinical implications of our results, we found correlations between UFP concentrations in EBC and clinical parameters as well as with inflammatory markers. Strong negative correlation was found between UFP concentrations and pack years. FEV 1 and DLCO were positively correlated with UFP concentrations. A low UFP concentration in EBC is a reflection of a high inflammatory state. UFP concentration in EBC was negatively correlated with systemic inflammation markers, peripheral eosinophil counts, and CRP and LDH levels in serum. Consistent with our findings, exhaled microparticles of surfactant protein A, a major component in the lung's immune system, were reduced in COPD patients compared with healthy subjects, and correlated negatively with disease severity. ${ }^{35}$

\section{Limitations}

There are several limitations to our study. First, since this was a cross-sectional study, reproducibility of the UFP content in EBC in the same subject was not evaluated. Second, the EBC UFP content as a reflection of alveolar membrane permeability can be influenced by other factors, such as comorbidities and medications. Last, the origin and chemical properties of UFP in EBC and serum samples are not clear. Our assumption is that measured particles are a mixture of exogenous and endogenous origin. Diesel exhaust particulate (DEP) constitutes the major fraction in urban particulate air pollution. ${ }^{36}$ The accumulation mode of DEP typically ranges from 30 to $500 \mathrm{~nm},{ }^{37}$ similarly to our particles that had a comparable size range, ie, D90 of $398 \mathrm{~nm}$ and $345 \mathrm{~nm}$ in EBC and serum samples, respectively.

\section{Conclusion}

This study suggests that UFP content in EBC reflects airway inflammation and oxidative stress. High UFP concentrations in serum of COPD patients support the hypothesis that increased epithelial permeability is responsible to low UFP content in EBC. Although further studies are warranted to demonstrate this mechanism, to the best of our knowledge, our data represent the first attempt to look at changes in UFP content in the airways of COPD patients in correlation with disease severity.

\section{Acknowledgment}

This work was supported by the Israel Lung Association.

\section{Disclosure}

The authors report no conflicts of interest in this work.

\section{References}

1. Li N, Georas S, Alexis N, et al. A work group report on ultrafine particles (American Academy of Allergy, Asthma \& Immunology): why ambient ultrafine and engineered nanoparticles should receive special attention for possible adverse health outcomes in human subjects. $J$ Allergy Clin Immunol. 2016;138(2):386-396.

2. Bar-Shai A, Alcalay Y, Sagiv A, et al. Fingerprint of lung fluid ultrafine particles, a novel marker of acute lung inflammation. Respiration. 2015;90(1):74-84.

3. Mathers CD, Loncar D. Projections of global mortality and burden of disease from 2002 to 2030. PLoS Med. 2006;3(11):e442.

4. Lange P, Celli B, Agustí A, et al. Lung-function trajectories leading to chronic obstructive pulmonary disease. N Engl J Med. 2015;373(2):111-122.

5. Gan WQ, Fitzgerald JM, Carlsten C, Sadatsafavi M, Brauer M. Associations of ambient air pollution with chronic obstructive pulmonary disease hospitalization and mortality. Am J Respir Crit Care Med. 2013;187(7): $721-727$.

6. Konstantinidi EM, Lappas AS, Tzortzi AS, Behrakis PK. Exhaled breath condensate: technical and diagnostic aspects. ScientificWorldJournal. 2015;2015:435160.

7. Fireman E, Lerman Y, Stark M, et al. A novel alternative to environmental monitoring to detect workers at risk for beryllium exposure-related health effects. J Occup Environ Hyg. 2014;11(12):809-818. 
8. Fireman E, Lerman Y, Stark M, et al. Detection of occult lung impairment in welders by induced sputum particles and breath oxidation. Am J Ind Med. 2008;51(7):503-511.

9. Benor S, Alcalay Y, Domany KA, et al. Ultrafine particle content in exhaled breath condensate in airways of asthmatic children. $J$ Breath Res. 2015;9(2):026001.

10. Horváth I, Hunt J, Barnes PJ, et al. Exhaled breath condensate: methodological recommendations and unresolved questions. Eur Respir J. 2005;26(3):523-548.

11. Dalle-Donne I, Giustarini D, Colombo R, Rossi R, Milzani A. Protein carbonylation in human diseases. Trends Mol Med. 2003;9(4):169-176.

12. Pellegrino R, Viegi G, Brusasco V, et al. Interpretative strategies for lung function tests. Eur Respir J. 2005;26(5):948-968.

13. Jones PW, Harding G, Berry P, Wiklund I, Chen WH, Kline Leidy N. Development and first validation of the COPD assessment test. Eur Respir J. 2009;34(3):648-654.

14. Geiser M, Kreyling WG. Deposition and biokinetics of inhaled nanoparticles. Part Fibre Toxicol. 2010;7(1):2.

15. Anderson PJ, Wilson JD, Hiller FC. Respiratory tract deposition of ultrafine particles in subjects with obstructive or restrictive lung disease. Chest. 1990;97(5):1115-1120.

16. Crotty Alexander LE, Shin S, Hwang JH. Inflammatory diseases of the lung induced by conventional cigarette smoke: a review. Chest. 2015; 148(5):1307-1322.

17. Zhou Z, Chen P, Peng H. Are healthy smokers really healthy? Tob Induc Dis. 2016;14:35.

18. Barnes PJ. Inflammatory mechanisms in patients with chronic obstructive pulmonary disease. J Allergy Clin Immunol. 2016;138(1):16-27.

19. MacNee W. Pathogenesis of chronic obstructive pulmonary disease. Proc Am Thorac Soc. 2005;2(4):258-266.

20. Chen L, Deng H, Cui H, et al. Inflammatory responses and inflammationassociated diseases in organs. Oncotarget. 2018;9(6):7204-7218.

21. Fazlollahi F, Kim YH, Sipos A, et al. Nanoparticle translocation across mouse alveolar epithelial cell monolayers: species-specific mechanisms. Nanomedicine. 2013;9(6):786-794.

22. Nemmar A, Hoet PHM, Vanquickenborne B, et al. Passage of inhaled particles into the blood circulation in humans. Circulation. 2002;105(4): 411-414.

23. Oberdörster G, Sharp Z, Atudorei V, et al. Extrapulmonary translocation of ultrafine carbon particles following whole-body inhalation exposure of rats. J Toxicol Environ Health A. 2002;65(20):1531-1543.

24. Oberdörster G, Oberdörster E, Oberdörster J. Nanotoxicology: an emerging discipline evolving from studies of ultrafine particles. Environ Health Perspect. 2005;113(7):823-839.
25. Miller MR, Raftis JB, Langrish JP, et al. Inhaled nanoparticles accumulate at sites of vascular disease. ACS Nano. 2017;11(5):4542-4552.

26. Xiong W, Xu M, Zhao Y, Wu X, Pudasaini B, Liu JM. Can we predict the prognosis of COPD with a routine blood test? Int J Chron Obstruct Pulmon Dis. 2017;12:615-625.

27. Sin DD, Man SFP. Systemic inflammation and mortality in chronic obstructive pulmonary disease. Can J Physiol Pharmacol. 2007;85(1): 141-147.

28. Thomsen M, Ingebrigtsen TS, Marott JL, et al. Inflammatory biomarkers and exacerbations in chronic obstructive pulmonary disease. JAMA. 2013;309(22):2353

29. Löndahl J, Swietlicki E, Rissler J, et al. Experimental determination of the respiratory tract deposition of diesel combustion particles in patients with chronic obstructive pulmonary disease. Part Fibre Toxicol. 2012;9(1):30.

30. Lavi A, Potchter O, Omer I, Fireman E. Mapping air pollution by biological monitoring in the metropolitan TEL Aviv area. Int J Environ Health Res. 2016;26(3):346-360.

31. Heinrich J, Schikowski T. COPD patients as vulnerable subpopulation for exposure to ambient air pollution. Curr Environ Health Rep. 2018; 5(1):70-76.

32. Guan WJ, Zheng XY, Chung KF, Zhong NS. Impact of air pollution on the burden of chronic respiratory diseases in China: time for urgent action. Lancet. 2016;388(10054):1939-1951.

33. Starosta V, Rietschel E, Paul K, Baumann U, Griese M. Oxidative changes of bronchoalveolar proteins in cystic fibrosis. Chest. 2006; 129(2):431-437.

34. Mcguinness AJA, Sapey E. Oxidative stress in COPD: sources, markers, and potential mechanisms. J Clin Med. 2017;6(2):E21.

35. Lärstad M, Almstrand AC, Larsson P, et al. Surfactant protein A in exhaled endogenous particles is decreased in chronic obstructive pulmonary disease (COPD) patients: a pilot study. PLoS One. 2015;10(12): e0144463.

36. Mazzarella G, Ferraraccio F, Prati MV, et al. Effects of diesel exhaust particles on human lung epithelial cells: an in vitro study. Respir Med. 2007;101(6):1155-1162.

37. Kittelson D, Watts W, Johnson J. Diesel Aerosol Sampling Methodology - CRC E-43. Minneapolis, MN: University of Minnesota; 2002. Available from: http://www.nanoparticles.org/pdf/Kittelson-Watts.pdf. Accessed February 19, 2019
International Journal of COPD

\section{Publish your work in this journal}

The International Journal of COPD is an international, peer-reviewed journal of therapeutics and pharmacology focusing on concise rapid reporting of clinical studies and reviews in COPD. Special focus is given to the pathophysiological processes underlying the disease, intervention programs, patient focused education, and self management protocols.

\section{Dovepress}

This journal is indexed on PubMed Central, MedLine and CAS. The manuscript management system is completely online and includes a very quick and fair peer-review system, which is all easy to use. Visit http://www.dovepress.com/testimonials.php to read real quotes from published authors. 